\title{
CORRIGENDUM
}

\section{Artemin is estrogen regulated and mediates antiestrogen resistance in mammary carcinoma}

\author{
J Kang, PX Qian, V Pandey, JK Perry, LD Miller, ET Liu, T Zhu, DX Liu and PE Lobie
}

Oncogene (2012) 31, 402; doi:10.1038/onc.2011.553

Correction to: Oncogene (2010) 29, 3228-3240; doi:10.1038/ onc.2010.71; published online 22 March 2010

The authors of the study have noticed two errors in the figures (Figure 1b and Supplementary Figure 1b) of the manuscript. These errors were inadvertently introduced during figure preparation and are not a correct representation of the data generated. The authors have now provided correct representative data for Figure $1 \mathrm{~b}$ and Supplementary Figure $1 \mathrm{~b}$. The errors in the original published manuscript do not in any way alter the results or conclusions of this study. The authors apologize that these errors were not detected earlier. b
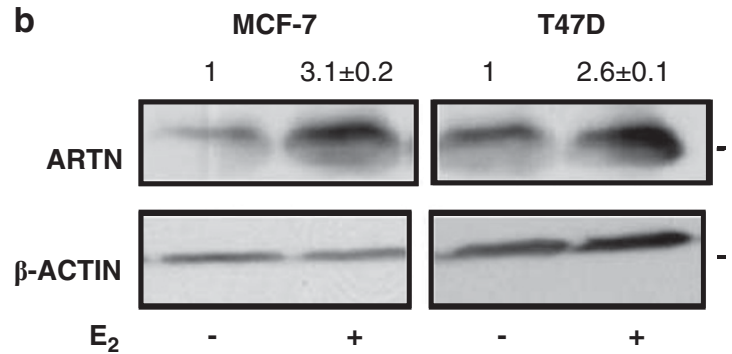

Figure $1 b$.

Supplementary Information accompanies the paper on the Oncogene website (http://www.nature.com/onc) 